\title{
Relato da história da inserção e evolução do atendimento psicológico a bebês e suas famílias em uma Unidade de Neonatologia
}

\author{
The history of the inception and evolution of psychological care for infants and their families \\ in a Neonatal Unit
}

Maria Silvia V. Setúbal'

\begin{abstract}
"Há muito mais continuidade entre a vida intrauterina e a primeira infância do que a impressionante cesura do ato do nascimento nos permite saber"
\end{abstract}

Sigmund Freud (1926)

\section{RESUMO}

Objetivo: Este artigo apresenta o histórico de atuação de uma psicóloga na área de Neonatologia e sua evolução, desde as primeiras tentativas de mudar certas rotinas da unidade para que favorecessem a humanização do atendimento até a sua completa inserção na equipe multidisciplinar. São descritas em detalhes as atuações específicas junto aos bebês e suas famílias no contexto da internação hospitalar, com o intuito de auxiliar os profissionais de saúde que trabalham na área de implementação de programas afins.

Descrição do caso: Relato da história de inserção e da evolução do trabalho de uma psicóloga na equipe de Neonatologia do Centro de Atenção Integral à Saúde da Mulher (CAISM) da Universidade Estadual de Campinas (Unicamp), num período de dez anos (1993 a 2003). Descrevem-se as atividades específicas da Psicologia, o embasamento teórico dos programas desenvolvidos na unidade e os recursos técnicos utilizados no atendimento à clientela.

Comentários: O saber específico do psicólogo pode ser estendido a toda a equipe, favorecendo ações de prevenção em Saúde Mental, principalmente a proteção da relação mãe-bebê. Além disso, pode ser disseminado, ganhar relevância e fazer parte do cotidiano de todas as unidades de terapia neonatais.

Palavras-chave: neonatologia; psicologia médica; equipe de assistência ao paciente; relações mãe-criança.

\section{ABSTRACT}

Objective: This article describes the evolution of a psychologist's work in a Neonatal Care Unit, from simple interventions that changed certain routines to foster humanization of care, to the complete integration of this professional into the multidisciplinary neonatal team. Detailed descriptions of the work's implementation in the hospital setting offer health professionals of the field a model for similar programs.

Case description: The history of the inception and evolution of a psychologist's work at the Neonatal Care Unit of Universidade Estadual de Campinas in a ten-year period (1993 to 2003) was described. Specific activities developed within this period have been described, as well as the theory supporting every action. The base techniques utilized within this time frame are also commented.

Comments: The specificity of the psychologist's knowledge can be extended to other health professionals of the same field, promoting preventive mental health measures, especially actions that benefit the bonding between mothers and their babies. It could also be disseminated, grow in importance, and become routine in every neonatal care unit.

Key-words: neonatology; psychology, medical; patient care team; mother-child relations.
Instituição: Centro de Atenção Integral à Saúde da Mulher (CAISM) da Universidade de Campinas (Unicamp), Campinas, SP, Brasil

'Ex-psicóloga do Serviço de Psicologia do CAISM-Unicamp, Campinas, SP, Brasil
Endereço de correspondência:

Maria Silvia V. Setúbal

604 Alleghany Street

Blacksburg, VA, 24060 - EUA

E-mail: silviasetubal@yahoo.com

Recebido em: 14/1/09

Aprovado em: 13/4/09 


\section{Introdução}

No início dos anos 1990, seguindo um plano nacional de humanização do atendimento hospitalar ${ }^{(1)}$, a equipe de Neonatologia do Centro de Atenção Integral à Saúde da Mulher (CAISM) da Universidade Estadual de Campinas (Unicamp) iniciou a implementação de uma série de mudanças na unidade. Até então, os recém-nascidos ficavam exclusivamente aos cuidados da equipe, que os isolava do contato com a família na tentativa de prevenir infecções e limitava a visita a poucas horas por semana, para que as mães trouxessem o leite ordenhado. Por sua vez, as mães, alijadas dos cuidados dos seus filhos e em pleno puerpério, demonstravam reações de impotência, fragilidade, culpa e temor em se aproximar dos bebês que, ligados a aparelhos e lutando para sobreviver, eram atendidos nas suas necessidades médicas imediatas, sem acesso ao afeto de suas famílias. No momento em que necessitavam mais intensamente um do outro, mãe e bebê estavam separados.

As teorias psicanalíticas a respeito do desenvolvimento emocional das crianças enfatizam a importância das primeiras relações do bebê com sua mãe na estruturação da psique. Melanie Klein ${ }^{(2)}$, na primeira metade do século 20, foi a primeira a postular a existência de mecanismos mentais muito primitivos, ampliando o alcance do tratamento psicanalítico a crianças cada vez mais jovens. Winnicott ${ }^{(3,4)}$, pediatra e psicanalista inglês, criticou o enfoque da pediatria nos anos 1950, que se preocupava em demasia com a higiene e o asseio e não se atentava às necessidades emocionais dos bebês e de suas mães. Suas teorias contribuíram muito para a reorganização dos cuidados com os recém-nascidos nas décadas seguintes. Klaus e Kennel ${ }^{(5,6)}$, Lacroix ${ }^{(7)}$ e Cramer ${ }^{(8)}$ desenvolveram estudos significativos sobre a importância do vínculo mãe-bebê e seus desdobramentos no desenvolvimento saudável.

Mas como fortalecer o vínculo mãe-bebê numa situação crítica de internação do recém-nascido? Algumas mudanças na unidade favoreceram de imediato a integração da mãe com o bebê prematuro ou doente: os nomes dos bebês foram acrescentados à ficha fixada ao leito e, dessa forma, a criança deixou de ser apenas "o RN da dona Maria" e adquiriu uma identidade própria. Os pais ganharam acesso irrestrito ao bebê durante a internação. $\mathrm{O}$ incentivo à amamentação foi reforçado com a abertura de um espaço específico no hospital para as mães retirarem o leite. O alojamento conjunto tardio foi implantado, propiciando às mães a oportunidade de cuidar de seus bebês em vias de alta sob supervisão da equipe, o que as reassegurava em suas capacidades de cuidar do bebê em casa. A equipe da Neonatologia, que se sensibilizou em relação à especificidade do atendimento psicológico no alívio dos sofrimentos psíquicos, buscou integrar a psicóloga na equipe multidisciplinar, para auxiliá-la a lidar com as dificuldades intensas vivenciadas diariamente: casos graves, morte, tempo prolongado de internação, angústias da família. Assim, em 1993, teve início a proposta de uma intervenção específica da Psicologia na unidade neonatal.

Os trabalhos de Françoise Dolto ${ }^{(9)}$ e de Caroline Elliacheff ${ }^{(10)}$ sobre os sofrimentos psíquicos inerentes ao ser humano desde o nascimento, e que se intensificam quando somados a sofrimentos físicos reais, serviram de base para esta proposta. Segundo Dolto, se esses sofrimentos emocionais não forem reconhecidos ou "ditos", causam "lacunas" no desenvolvimento harmônico dos seres humanos, propiciando a instalação de quadros psicossomáticos. Palavras significativas e verdadeiras, que dizem respeito à identidade do bebê e à sua história, preencheriam as "lacunas", permitindo a elaboração de situações de fragilidade psíquica e refazendo o curso natural e harmônico do desenvolvimento. Elliacheff ampliou a importância da palavra dita, como aquela que confere existência social e simbólica à criança desde o seu nascimento. Assim, contrariamente ao que se pensou durante muito tempo, o bebê é sensível à palavra, pois embora não tenha ainda a capacidade da fala, é um ser humano destinado a falar. Falar diretamente aos bebês, contar-lhes a sua história de vida, aliviá-los da angústia do não dito, possibilitaria dar um significado à dor e aos sofrimentos físicos a que são submetidos: a palavra seria vista como tratamento, assim como o surfactante exógeno ${ }^{(11)}$, a fisioterapia respiratória ou a transfusão de sangue.

No início, porém, a interpretação dos sofrimentos psíquicos de bebês tão pequenos intrigava a equipe. Será que essa intervenção com as palavras teria algum efeito? Dizer ao bebê que ele estava hospitalizado porque nascera prematuro ou que sua mãe viria vê-lo todos os dias parecia pouco relevante para confortá-lo. No entanto, faltava ainda a contextualização da história dos bebês. Como recuperar essa história de maneira mais sistemática? Como passar essa história aos bebês? Ninguém parecia mais adequado para exercer essa função do que os próprios pais. Mas como orientá-los quanto à importância de suas palavras no acolhimento emocional do filho hospitalizado? Mesmo com acesso irrestrito aos seus bebês, muitas mães e pais tinham dificuldades em lidar com a situação de internação devido às emoções intensas e contraditórias vivenciadas. Optou-se, então, pela formação de um grupo 
de apoio emocional aos pais, no qual a troca de experiências entre eles serviria de continência ao longo da internação de seus bebês. Os pais, apoiados pelo grupo, contidos nos seus sofrimentos psíquicos, estariam mais aptos a conter os sofrimentos emocionais dos bebês internados.

\section{Descrição da intervenção}

As primeiras reuniões do Grupo de Pais de Bebês Internados na Neonatologia ocorreram em meados de 1996, lideradas pela psicóloga e por uma enfermeira. Aos poucos, outros profissionais, como o médico e a assistente social, passaram a participar ativamente das reuniões.

O grupo se caracterizou por ser um espaço aberto, de acesso livre e espontâneo. Havia pais que tinham acabado de entrar na unidade e pais que já estavam lá há meses, tendo passado por diversas fases de elaboração da situação e cujo testemunho encorajava os recém-chegados a enfrentar a dor da situação.

Como é possível deixar o bebê no hospital e ir para casa após terem vivenciado sua presença permanente ao longo da gestação? A noção de "falta" se instala concretamente e gera a angústia de não poder cuidar do filho, não poder pegá-lo no colo, de não poder amamentá-lo. Exacerbada pelo medo da morte, a falta despertava também crenças nas mulheres de serem mães más, que não puderam evitar o sofrimento do filho ou gerar um bebê saudável. Os sentimentos de impotência as levavam a pensar que os profissionais de saúde estariam em melhores condições de cuidar de seus filhos. As mães sentiam inveja particularmente das mulheres da equipe que podiam estar com o bebê o tempo todo e que passavam a ser vistas como mães substitutas mais capazes: "Ele está melbor na incubadora do que no meu colo", diziam. Com sua maternidade ameaçada, elas temiam não serem reconhecidas como mães pelos seus bebês. O grupo as estimulava quanto à importância do seu papel: "Ninguém pode dar aos seus filhos o seu afeto, o seu cheiro, o seu leite, o seu amor", que são as referências fundamentais para que o bebê se desenvolva. Essas palavras verdadeiras possibilitavam que a ambivalência materna fosse aplacada e cada mãe pudesse ousar ser a mãe mais adequada possível, dadas as circunstâncias em que se encontrava.

As dificuldades com a amamentação, desde a retirada e armazenamento até o transporte do leite para a unidade, eram discutidas em quase todos os encontros. As mães sentiam-se incapazes de retirar o leite, esgotadas física e psiquicamente pelo esforço e pela frustração. As dificuldades em levar o bebê ao seio, a aparente falta de colaboração deles para abocanharem, o fato de não poderem receber o afeto e o alimento diretamente delas, as frustravam. Ao se reforçar a importância do leite materno como ponte entre cada mãe e seu bebê, ou seja, a manutenção do fluxo do leite como algo equivalente ao fluxo do afeto, permitia-se que as mães se sentissem mais capazes e menos ambivalentes em seu papel de provedoras.

A aparelhagem, as sondas e os tubos amedrontavam os pais, como se fossem semelhantes a instrumentos de tortura. $\mathrm{O}$ uso de analogias que comparavam bebês prematuros a frutas que caem do galho mais cedo e a aparelhagem aos recursos utilizados para amadurecer essas frutas verdes fazia com que os pais aceitassem tais aparelhos como instrumentos de auxílio na recuperação dos filhos. Os bebês-banana eram aqueles que amadureciam sem qualquer ajuda externa, os bebês-mamão necessitavam ser "riscados", embrulhados no jornal, e os bebês-caqui precisavam de gotinhas de vinagre. Esse exercício facilitava a compreensão e aceitação da parafernália tecnológica a serviço do amadurecimento dos bebês.

Há muito que os pais podem fazer pelos seus filhos, mesmo quando se sentem impotentes diante do bebê inerte, ligado a aparelhos, dormindo. Procurava-se ressaltar a importância do afeto, do toque, de chamar o filho pelo nome escolhido, de lhe contar a sua própria história de vida (desde o desejo de concebê-lo, passando pela história da gestação e do nascimento, até a sua internação) para a integração desse filho em suas vidas. O reconhecimento do bebê como filho, mesmo sendo tão diferente daquele que esperavam, favorecia a relação entre os pais e eles. Os pais, em geral, tranquilizavam-se com a ressignificação de seus papéis e com a sua relevância na recuperação dos filhos, e as vindas ao hospital ganhavam novo sentido. Os pais nos contavam como os bebês reagiam à sua presença e às suas palavras ditas em voz alta: abriam os olhos, se mexiam no berço, davam sinais de comunicação e de reconhecimento: ao serem reconhecidos, reconheciam! Os pais se sentiam mais aptos a auxiliarem seus bebês na recuperação, sem pensar tanto em seus próprios sofrimentos. Os bebês passaram a ser vistos como seres mais capazes, mais fortes, que numa circunstância tão adversa lutavam para viver.

Abrindo espaço para os homens nas reuniões, foi possível explorar seus sentimentos de dor e angústia diante da internação de um filho, bem como as maneiras mais comuns de lidarem com a situação: ser forte, não demonstrar tristeza (pois a mãe precisa de apoio), tocar a vida diária normalmente, evitar falar da situação de internação e doença para não se emocionarem. Essa forma de lidar com o sofrimento 
psíquico, tão comum a esses homens, acabava por afastá-los das companheiras, deixando-as frustradas em relação às suas necessidades de atenção e apoio. Quando os pais participavam do grupo e falavam de suas experiências, encontravam continência para elaborar a dor psíquica intensa e se aproximarem mais dos seus bebês e de suas companheiras.

As mães se preocupavam muito com seus outros filhos que, privados da presença do bebê internado, tinham comportamentos agressivos e regredidos. Os pais, assoberbados com a internação do bebê, não sabiam como lidar com os outros filhos. A literatura científica ${ }^{(12-15)}$ que aborda a visita de crianças a unidades neonatais foi o substrato teórico para a elaboração do protocolo "A visita dos irmãos e avós à unidade neonatal" que, ao ser implantado, permitiu que os irmãos e avós dos bebês tivessem acesso à unidade durante a internação, favorecendo a integração da família.

A dificuldade em compreender a linguagem médica levava os pais a sentirem-se enganados e incapacitados. Eles eram incentivados, no grupo, a descreverem alguma atividade da sua profissão: a costureira usava termos tais como chulear ou bainha; o mecânico consertava ventoinhas e carburadores e, quando indagados sobre o significado desses termos, percebiam a dificuldade de substituí-los por outros mais simples. Dessa forma, compreendiam que a linguagem médica não era utilizada para excluí-los ou enganá-los, mas por ser de uso comum entre os médicos e de difícil "tradução".

O grupo de pais possibilitou também uma maior integração da equipe. Os diversos profissionais envolvidos nessa atividade puderam conhecer melhor o trabalho dos outros, apoiar-se mutuamente e buscar soluções em conjunto para as demandas específicas de sua clientela. A maior integração da equipe permitiu o surgimento do Grupo de Paliativos, em 2002 $2^{(16)}$, para a discussão de questões éticas, médicas e psíquicas relacionadas à vida e à morte no caso de bebês sem prognóstico. Em seguida, escreveu-se o protocolo Acolbimento ao óbito em UTI neonatal, que evoluiu para as reuniões com os pais dos bebês que morrem na unidade: Grupo de Retorno de Pais Enlutados.

\section{Comentários}

Passados 15 anos desde a inserção e atuação da psicóloga na equipe de Neonatologia do CAISM, trabalhos recentes de dois neurocientistas, Kandell ${ }^{(17)}$, sobre memória, e Doidge ${ }^{(18)}$, sobre a plasticidade do cérebro, corroboraram o embasamento teórico utilizado neste trabalho. Por meio de experimentos laboratoriais e tomografias computadorizadas, esses cientistas comprovaram a importância das primeiras vivências infantis no desenvolvimento emocional do ser humano. Kandel demonstrou que muitas das nossas memórias emocionais (implícitas) existem desde o nascimento e são anteriores ao estabelecimento da fala, o que confirma a existência de memórias inconscientes que, se forem traumáticas, poderão ser evocadas em situações similares ao longo da vida e gerar conflitos psíquicos. Doidge ${ }^{(18)}$ afirmou que é na primeira infância que áreas-chave do lobo frontal direito se desenvolvem e formam os circuitos neuronais que permitirão ao bebê manter suas ligações afetivas com outros seres humanos e regular suas emoções. Outros neurocientistas ${ }^{(19)}$ reforçam a ideia de que a intervenção psicoterápica facilitaria mudanças das informações adquiridas ao longo da vida de uma pessoa, pois reforçaria determinadas sinapses e enfraqueceria outras, comprovando a ação terapêutica das palavras verdadeiras. A literatura atual sobre cuidados com bebês internados reconhece a importância de um trabalho multidisciplinar nas unidades neonatais ${ }^{(20,21)}$ e propõe a revisão da assistência em Neonatologia ${ }^{(22,23)}$ para que se criem condições melhores de preservação da relação mãe-bebê. O modelo mais disseminado é o da inclusão da família no processo de internação e a participação ativa dos pais no tratamento dos filhos ${ }^{(24-26)}$.

A criação do grupo de pais e os outros programas e protocolos implementados na unidade de Neonatolgia do CAISM foram obra do esforço conjunto de um grupo de profissionais dinâmico, ativo e interessado em expandir suas ações e ideias: um trabalho constante de interação, troca e busca de substrato teórico para cada etapa implantada; um trabalho de vários anos, incorporando novos saberes, discutindo cada fase do processo e que não se esgota nas ideias apresentadas neste artigo.

É gratificante constatar o quanto o saber específico do psicólogo, integrado a uma equipe multidisciplinar, pôde contribuir para o atendimento aos bebês e suas famílias. As principais contribuições da Psicologia à unidade foram promover a ampliação do pensar da equipe e propor ações específicas que pudessem potencializar os efeitos do cuidado altamente especializado, além de motivar a humanização do atendimento e a prevenção em saúde mental.

É importante que esse saber possa ser disseminado, ganhar relevância e fazer parte do cotidiano de todas as unidades de terapia neonatais, e que a relação entre pais e bebês internados, que começa truncada e cheia de fantasmas, possa ser resgatada e protegida por uma equipe instrumentalizada e atenta, para que o recém-nascido se desenvolva adequadamente ao longo de sua vida. 


\section{Agradecimentos}

Ao Doutor Sérgio Tadeu Marba, diretor do serviço de Neonatologia do CAISM- Unicamp, pelo apoio incondicional ao desenvolvimento deste trabalho na unidade. A toda a equipe do Serviço de Neonatologia do CAISM-Unicamp ao longo dos 10 anos de trabalho conjunto, especialmente à Doutora Jussara de Lima e Souza, à Doutora Maria Otilia Bianchi, à Doutora Silvia Maria Monteiro da Costa, às enfermeiras Paula Maria Cinira Batista, Sônia Mara dos Santos Cardoso, assistente social Elai-

\section{Referências bibliográficas}

1. Casate JC, Corrêa AK. Humanização do atendimento em saúde: conhecimento veiculado na literatura brasileira de enfermagem Rev Latino-Am Enferm 2005;13:105-11.

2. Klein M. Contribuições à psicanálise. São Paulo: Mestre Jou; 1981.

3. Winnicott DW. Da pediatria à psicanálise. Rio de Janeiro: Francisco Alves; 1978.

4. Winnicott DW. A criança e seu mundo. São Paulo: Zahar; 1979.

5. Klaus M, Kennel J. O surpreendente recém-nascido. Porto Alegre: Artes Médicas; 1995.

6. Klaus M, Kennel J. Pais/bebês: a formação do apego. Porto Alegre: Artes Médicas; 1996.

7. Lacroix MB, Monmayrant M. A observação de bebês: os laços do encantamento. Porto Alegre: Artes Médicas; 1997.

8. Cramer B, Palacio-Espasa F. Técnicas psicoterápicas mãe-bebê. Porto Alegre: Artes Médicas; 1993.

9. Dolto F. No jogo do desejo: ensaios clínicos. $2^{\text {nd }}$ ed. São Paulo: Ática; 1996.

10. Elliacheff C. Corpos que gritam: a psicanálise com bebês. São Paulo: Ática; 1995.

11. Miyoshi MH, Guinsburg R, Kopelman BI, Rodrigues AS, Kantorowitz J. Terapêutica de reposição de surfactante exógeno em recém-nascidos prematuros com síndrome do desconforto respiratório. Brazilian Pediatric News [serial on the Internet]. 1999;1(1) [Cited 2009 Jul 29]. Available from: http://www.brazilpednews.org.br/marco99/ao99002.htm

12. Ballard JL, Maloney M, Shank M, Hollister L. Sibling visits to a newborn intensive care unit: implications for siblings, parents, and infants. Child Psychiatry Hum Dev 1984;14:203-14.

13. Meyer EC, Kennaly KF, Zika-Beres E, Cashore WJ. Attitudes about sibling visitation in the neonatal intensive care unit. Arch Pediatr Adolesc Med 1996;150:1021-6.

14. Morsch D, Carvalho M, Lopes JM. Programa de acompanhamento e visitação aos irmãos de bebês internados em UTI neonatal. Pediatria Mod 1997;33:481-7 ne Aparecida de Carvalho Salcedo, às psicólogas Elisa Maria Pierina e Cláudia Aparecida Marchetti Duarte pelas parcerias, disponibilidade, abertura e respeito mútuo que contribuíram imensamente para a formação profissional da autora. À psicóloga Maria Nurymar Brandão Benetti pela introdução dos trabalhos com bebês, inestimável parceria teórica e prática na implementação dessas ideias na unidade de Neonatologia do CAISM e pela grande amizade. À professora Doutora Belinda Mandelbaum, que cumpriu um papel fundamental no resgate desse material e no apoio para torná-lo público.

15. Schwab F, Tolbert B, Bagnato S, Maisels J. Sibling visiting in a neonata intensive care unit. Pediatrics 1983;71:835-8.

16. Costa SM, Duarte CA, Salcedo AC, Perina M, Souza JL, Bianchi MO et al. Cuidados paliativos em neonatologia. Mundo Saúde 2003;27: 171-5.

17. Kandel ER. In search of memory: the emergence of a new science of mind New York: Norton; 2006.

18. Doidge $\mathrm{N}$. The brain that changes itself: stories of personal triumph from the frontiers of brain science. New York: Penguin; 2007.

19. Liggan DY, Kay J. Some neurobiological aspects of psychotherapy: a review. J Psychother Pract Res 1999;8:103-14.

20. Tavares GR, Mota JA, Magro C. A systemic vision of prematurity: the relationship between family and health professionals facing the preterm baby in NICU. Rev Paul Pediatr 2006;24:27-34.

21. Gomes AL. The bond mother preterm newborn infant: possibilities of intervention multi-professional team. Psicol hosp (São Paulo) [serial on the Internet]. São Paulo dic 2004;2(2) [Cited 2009 Jul 29]. Available from: http://pepsic.bvs-psi.org.br/scielo.php?script=sci_arttext\&pid=S1677$74092004000200004 \&$ Ing=es\&nrm=iso

22. Lubbe W. Early intervention care program for parents of neonates. Curationis 2005;28:54-63.

23. Heermnn JA, Wilson ME, Wilhelm PA. Mothers in the NICU: outsider to partner Pediatr Nurs 2005;31:176-81.

24. Griffin T. Family-centered care in the NICU. J Perinat Neonatal Nurs 2006;20:98-102.

25. Wigert $H$, Johansson $R$, Berg M, Hellström AL. Mothers' experiences of having their newborn child in a neonatal intensive care unit. Scand J Caring Sci 2006;20:35-41.

26. Cleveland LM. Parenting in the neonatal intensive care unit. J Obstet Gynecol Neonatal Nurs 2008;37:666-91. 